University of Wollongong

Research Online

Faculty of Social Sciences - Papers (Archive) Faculty of Arts, Social Sciences \& Humanities

$1-1-2017$

\title{
Understanding carers' lived experience of stigma: the voice of families with a child on the autism spectrum
}

Timothy Broady

Carers NSW, trb816@uow.edu.au

Gerard J. Stoyles

University of Wollongong, stoyles@uow.edu.au

Corinne Morse

University of Wollongong

Follow this and additional works at: https://ro.uow.edu.au/sspapers

Part of the Education Commons, and the Social and Behavioral Sciences Commons

Research Online is the open access institutional repository for the University of Wollongong. For further information contact the UOW Library: research-pubs@uow.edu.au 


\title{
Understanding carers' lived experience of stigma: the voice of families with a child on the autism spectrum
}

\begin{abstract}
Existing research suggests that there are several unique challenges associated with caring for a child on the autism spectrum. Despite a growing evidence base regarding autism spectrum disorders and their increasing prevalence, children on the autism spectrum and their families continue to perceive stigmatisation from various sources throughout the community. These perceptions of stigma can profoundly impact the quality of life of these children and their carers alike. This exploratory study sought to investigate carers' perceptions of stigma in caring for a child with high functioning autism. Fifteen carers from Sydney and the South Coast regions of New South Wales, Australia, participated in semistructured interviews regarding their caring experiences and any perceived encounters with stigma. Four domains of stigmatising experiences were identified: (i) lack of knowledge, (ii) judgement, (iii) rejection and (iv) lack of support. These domains were each reported to exist in four main contexts: (i) school, (ii) public, (iii) family and (iv) friends. These domains and contexts established a framework which provided a detailed account of how and where carers felt stigmatised, including the suggestion of a stigmatising pathway through the four domains. The main contexts in which stigma was perceived also appeared to be related, with those carers who experienced stigma in one context being more likely to report similar experiences in other contexts. Any attempts to empower carers in the face of stigmatisation should therefore consider each of these domains, the pathway that connects them and the relationship between different social contexts. Through identifying this pathway, supportive services can be acutely aware of how carers may perceive potentially stigmatising experiences and therefore provide appropriate interventions or support for the relevant stage of the pathway.
\end{abstract}

\section{Keywords}

autism, child, families, voice, spectrum, stigma, understanding, experience, carers, lived

\section{Disciplines}

Education | Social and Behavioral Sciences

\section{Publication Details}

Broady, T. R., Stoyles, G. J. \& Morse, C. (2017). Understanding carers' lived experience of stigma: the voice of families with a child on the autism spectrum. Health and Social Care in the Community, 25 (1), 224-233. 


\title{
Understanding carers' lived experience of stigma: The voice of families with a child on the autism spectrum
}

\author{
Timothy R. Broady \\ Gerard Stoyles ${ }^{2}$ \\ Corinne Morse ${ }^{2}$ \\ ${ }^{1}$ Carers NSW, Australia \\ ${ }^{2}$ University of Wollongong, Australia
}

This is an Author Accepted Manuscript of an article published in Health and Social Care in the Community, 2017, Vol. 25(1), 224-233.

DOI: $10.1111 /$ hac. 12297 


\begin{abstract}
Existing research suggests that there are several unique challenges associated with caring for a child on the autism spectrum. Despite a growing evidence base regarding autism spectrum disorders and their increasing prevalence, children on the autism spectrum and their families continue to perceive stigmatisation from various sources throughout the community. These perceptions of stigma can profoundly impact the quality of life of these children and their carers alike. This exploratory study sought to investigate carers' perceptions of stigma in caring for a child with high functioning autism. Fifteen carers from Sydney and the South Coast regions of New South Wales, Australia, participated in semistructured interviews regarding their caring experiences and any perceived encounters with stigma. Four domains of stigmatising experiences were identified: (i) lack of knowledge, (ii) judgement, (iii) rejection and (iv) lack of support. These domains were each reported to exist in four main contexts: (i) school, (ii) public, (iii) family and (iv) friends. These domains and contexts established a framework which provided a detailed account of how and where carers felt stigmatised, including the suggestion of a stigmatising pathway through the four domains. The main contexts in which stigma was perceived also appeared to be related, with those carers who experienced stigma in one context being more likely to report similar experiences in other contexts. Any attempts to empower carers in the face of stigmatisation should therefore consider each of these domains, the pathway that connects them and the relationship between different social contexts. Through identifying this pathway, supportive services can be acutely aware of how carers may perceive potentially stigmatising experiences and therefore provide appropriate interventions or support for the relevant stage of the pathway.
\end{abstract}

\title{
Keywords
}

Carers, high functioning autism, stigma

\section{Introduction}

Families with a child on the autism spectrum experience certain challenges and demands within the family and broader social contexts. These challenges can significantly vary, depending on the severity of the child's autistic symptoms and functional impairments, which vary greatly across the spectrum (Gray 2003, Lee 2009, Fletcher et al. 2012, Lilley 2013). This project focuses on the experiences of families of children diagnosed with highfunctioning autism (HFA). In particular, this paper investigates stigma across a range of social domains as perceived by parents of children with HFA, referred to as 'carers' throughout this paper. 'Carer' has specific meaning beyond the role of a parent, in referring to any individual who provides unpaid care for a family member or friend who has a disability, such as autism.

\section{Caring for a child with high-functioning autism}

When a child is diagnosed with HFA, the effects can extend throughout the entire family. Previous literature indicates that carers can experience emotional stressors from the initial experience of diagnosis and related to their ongoing caring roles. They take on additional caring responsibilities beyond those of a typical parent, including, but not limited to, the need to maintain a structured environment for their child, finding time for their own self-care, having to attend multiple therapeutic appointments and sourcing other structures of support (Gray 2003, Rocque 2010, Fletcher et al. 2012, Lutz et al. 2012, Gill \& Liamputtong 2013). Demands such as these have been found to result in increased financial burden, decline in martial harmony and a degree of self-neglect (Gray 2002, 2003, Fletcher et al. 2012, Gill \& Liamputtong 2013). 
Caring for a child on the autism spectrum has also been associated with negative psychological and physical health outcomes (Gray 2002, 2003, Estes et al. 2009, Fletcher et al. 2012, Griffith et al. 2012, Gill \& Liamputtong 2013). Research has shown that compared to those caring for typically developing children or children with other disorders, carers of children on the autism spectrum report higher rates of mental health issues, including stress, anxiety and depression (Olsson \& Hwang 2001, Green 2003).

Carers have similarly reported negative experiences in broader social settings. Autism is characterised by certain behavioural tendencies, many of which do not fit within social norms. Carers may therefore contend with hostile stares, insensitive comments and blatant exclusion from members of the general public when their child's behaviour is interpreted as socially unacceptable (Gray 1993, 2002, 2003, Green 2003, Estes et al. 2009, Ryan 2010). These experiences often leave carers feeling humiliated, judged and socially excluded (Farrugia 2009). Isolating experiences such as these are not limited to the general public. Studies have also shown that a large proportion of carers perceive a lack of understanding, empathy and support from their own family and friends with respect to the daily challenges required to support a child with a disability (Gray 2002, 2003, Green 2003, Gill \& Liamputtong 2013). This suggests that carers of children on the autism spectrum experience a degree of stigmatisation within the family, as well as broader social and community contexts.

In Australia, a number of services are available to carers of children on the autism spectrum. For example, non-profit organisations such as Autism Spectrum Australia (Aspect) exist to support people with autism, their families and carers by providing education, workshops, advice and support groups. Similarly, a national Network of Carers Associations exists to support and advocate for carers, including carers of children on the autism spectrum. Additionally, government-led initiatives (e.g. Helping Children With Autism, Autism Advisor Program, Early Days, Positive Partnerships) provide funding, information and community connections in order to support people on the autism spectrum and their families. Despite these formal support options, the literature suggests that carers continue to experience stigma from various sources in their lives.

\section{Stigma in general}

Stigma occurs when an individual is seen to possess an attribute that deviates from society's stereotype of what is 'normal', effectively devaluing and reducing the individual from 'a whole and usual person to a tainted, discounted one' (Goffman 1963). Several authors (e.g. Scambler \& Hopkins 1986, Jacoby 1994) suggest that stigma can be best understood through a differentiation between 'felt' and 'enacted' stigma. enacted stigma refers to receiving negative treatment as a result of a stigmatising condition, while felt stigma refers to feelings of embarrassment or shame associated with such treatment, and the fear of enacted stigma occurring. Scambler and Hopkins (1986) found that felt stigma was far more widespread than enacted stigma, and was also the cause for much greater distress. Felt stigma influences the manner in which an individual views the world and interprets events around them, often prompting them to go to concerted lengths to appear 'normal' (Gray 2002, Scambler 2004). The differentiation between felt and enacted stigma was initially developed in relation to epilepsy, and this distinction has been used as an appropriate theoretical framework throughout broader chronic illness literature (Scambler 2004).

Stigma does not necessarily only affect the individual with stigmatising attributes, but can extend to other close social connections, particularly family members. Through sharing interpersonal links with a stigmatised person, others may be seen to share their 'spoiled' social identity - a phenomenon known as 'courtesy stigma' (Goffman 1963). Carers (and 
other family members) of children on the autism spectrum may therefore be viewed by others as sharing features of the child's stigmatised disability.

The sharing of stigma between children with disabilities and their carers has been noted throughout the literature (Gray 2002, McKeever \& Miller 2004). For example, Ryan and Runswick-Cole (2008) argue that mothers of children with a disability experience a form of disablism emerging from a traditional medical model of disability which emphasises the burden of having a child with a disability. This disablism is argued to occur through discrimination directed at their children, in both attitude and action (Ryan \& Runswick-Cole 2008). Furthermore, the more that carers feel that people with disabilities are stigmatised in wider society, the more likely they are to report experiencing courtesy stigma themselves (Green 2003).

Pryor et al. (2012), in their theoretical explanations of stigma, described two social reactions to stigma, namely 'reflexive' and 'deliberative'. Reflexive reactions to stigma are immediate and are mostly emotionally based. Deliberative reactions to stigma are more carefully thought out, featuring a pausing effect in deciding on the social appropriateness of reacting negatively to the stigmatised person. The more controllable a stigmatising feature, the more acceptable it is to have a negative reaction (Pryor et al. 2004). Reflexive and deliberative stigma describe an interplay between the immediate response (reflexive) and the thought out response (deliberative), whereby the final reaction to a stigmatised person is a combination of both (Pryor et al. 2004).

Werner and Shulman (2015) unexpectedly found that carers of stigmatised individuals (including children on the autism spectrum) believed that other families in situations similar to theirs internalised the effects of stigma more than they did themselves. They hypothesised that carers' self-reporting of lower stigma reduced the distress of stigma that they felt on behalf of their children. It is therefore possible that the effects of the dual processing of reflexive and deliberative stigma might exercise a cumulative and erosive effect on the carers' self-image.

\section{Autism, carers and stigma}

Several authors suggest that children with HFA and their families are more stigmatised than families of children with other disorders (e.g. Down syndrome, cystic fibrosis), or even other children on the autism spectrum (Olsson \& Hwang 2001, Gray 2002, 2003, Griffith et al. 2012, Gill \& Liamputtong 2013). Due to the child's normal physical appearance and capacity to communicate, HFA is unlikely to be a noticeable condition to the general community (Olsson \& Hwang 2001, Gray 2002, 2003, Gill \& Liamputtong 2013, Lilley 2013). Therefore, when a child with HFA publicly displays any of the socially unacceptable behaviour associated with autism, such as a 'meltdown', observers may interpret this as bad behaviour or poor parenting, rather than as a symptom of an underlying condition (Gray 2002).

Through such experiences, carers have been found to demonstrate elevated emotional distress, internalise feelings such as shame, guilt, resentment and embarrassment, and experience poorer subjective well-being (Green 2003, Ludlow et al. 2012, Werner \& Shulman 2013). Furthermore, anticipating or fearing the prospect of stigma may lead carers to withdraw from social situations, isolate themselves and thus provide fewer opportunities for their children or themselves to positively interact with others (Green 2003, Woodgate et al. 2008).

Despite the negative ramifications of both felt and enacted stigma, the literature clearly indicates the resilience and adaptive abilities of carers (e.g. Landsman 1998, Green 2001, 
Broady 2013). Carers of children with a disability have reported developing advocacy skills and competence in mediating their children's interactions with wider social environments, and also emphasise the positive and enriching experiences of caring for a loved one (Ryan 2005, Blum 2007, Ryan \& Runswick-Cole 2008, Broady 2013, Carers NSW 2014). Previous research has also suggested that carers utilise a number of strategies to cope with any stress associated with their caring role, including support from family and friends, and accessing formal support services, and advocacy or support groups (Gray 2006, Carers NSW 2014). As opposed to seeking support, other carers have reported coping by withdrawing from social situations to avoid stress and potentially stigmatising experiences (Green 2003, Gray 2006). The importance of an individual carer's frame of mind has also been demonstrated by those who choose to interpret stigmatising experiences as emanating from a lack of awareness rather than reflecting malevolent motives. Such a viewpoint may lead carers to attempt to educate those they are in regular contact with, in order to reduce future stigma (Green 2003).

\section{Current study}

This exploratory study investigates the lived experience of stigma among carers of children with HFA. In particular, carers' views of how they have been stigmatised, and by whom, will be explored. Recurring themes throughout carers' narratives of stigma will be identified, and the commonalities between individuals will inform a discussion into potential coping mechanisms and support strategies for these carers, their children and their families.

\section{Method}

The study was promoted through a number of autism carer support groups. Potential participants were invited to contact the authors, who mailed them an information pack containing a Participant Information Sheet, a copy of the interview guide and a consent form with a reply paid envelope for its return. This convenience sampling method was selected to ensure participants' voluntary participation in a discussion involving potentially sensitive issues. The recruitment networks utilised likely contributed to the similar socio-demographic characteristics of participants outlined below.

Fifteen carers (nine female, six male) of children diagnosed with HFA participated in semistructured interviews, which were conducted at a time and location of their choice (either home or workplace). As suggested by scholars such as Bertaux (1981), this was considered to be a sufficient sample size to achieve saturation of data from qualitative interviews. The interviews took place throughout July and August 2013. Twelve participants were married (including six participants who were married couples), while one participant was separated and two were divorced. Their children ranged in age from 5 to 19 years $(\mathrm{M}=10.00, \mathrm{SD}=$ 4.28). The time since receiving a diagnosis of HFA ranged from 6 months to 11 years $(\mathrm{M}=$ $4.86, \mathrm{SD}=3.79$ ). The purpose of having a broad age range and time since diagnosis was to investigate parents' perceptions of the influence of their child's HFA on themselves and their child, particularly in relation to ongoing stigmatisation.

Interviews covered topics related to the experience of caring for a child with HFA and issues of stigma. Guided by previous literature and participants' personal stories, the interviews took an exploratory approach to understanding how carers understood stigma in their caring role. Broadly speaking, interviews covered the initial receiving of the child's HFA diagnosis, the nature of carers' involvement in support groups, the daily experience of caring for a child with HFA, carers' understanding of stigma and any personal experiences of feeling stigmatised. Interviews were audio-recorded and transcribed verbatim. Transcripts were deidentified and all participants were assigned pseudonyms. Transcripts were then collectively analysed using a thematic approach to identify domains of common experience between 
participants, and how these related to the existence of stigma. Themes were derived from salient statements made by participants. All three authors reviewed the interview transcripts independently to identify relevant comments regarding participants' stigmatising experiences and collate similar statements into overarching themes. They then jointly discussed their findings, and developed a framework of common domains to guide the interpretation of data. This collective approach to analysis ensured an acceptable level of agreement between all three authors and therefore enhanced the reliability of the findings presented below. Ethics approval for this study was granted by the University of Wollongong Human Research Ethics Committee.

\section{Results}

Four domains of stigmatising experience were evident throughout the interviews: (i) lack of knowledge, (ii) judgement, (iii) rejection and (iv) lack of support. These domains reflect participants' tangible experiences of this theoretical concept. As will be referenced throughout this section, these domains encapsulate contextual examples of felt, enacted and courtesy stigma.

Furthermore, these domains appeared to exist across four specific contexts: (i) school, (ii) public, (iii) family and (iv) friends. These contexts represent the vast majority of all sources of social interaction that these carers are likely to encounter, highlighting the pervasive nature of their felt stigma. However, the specific dynamics of each domain of stigma played out differently across these contexts, providing a more nuanced picture (particularly of felt stigma) as perceived by participants.

Despite the apparent pervasive nature of stigma in participants' lives, they also demonstrated significant levels of resilience through employing various coping mechanisms and strategies in response to any stigma.

\section{Lack of knowledge}

Other people's lack of knowledge about autism was seen to be a major contributor to stigmatising experiences, as suggested by comments such as 'ignorance is the biggest issue we face' (Allan). Every interviewed carer reported a lack of knowledge and experience of autism within school communities, demonstrated by Nicole, who said, 'the teacher . . . very limited experience in autism'. There was a sense of stigmatisation in that teachers displayed understanding of other students' learning disorders or medical conditions, but were not seen to give the same consideration to autism. Rather, they focused on the child's behaviour: 'autism gets forgotten because the behaviour is there' (Carol). In this sense, a lack of awareness around autism was perceived through seemingly unfair treatment from schools, both for the carers and their children. This lack of understanding was also seen to extend beyond the school into the general public: 'other parents just don't understand' (Kimberly); 'Basically, they are just ignorant' (Peter). The comments presented here demonstrate a worldview that interprets a lack of knowledge regarding autism as contributing to felt stigma.

At a more personal level, participants reflected on a lack of knowledge within their own family and friendship circles, making comments such as: 'my parents just don't get it' (Tammy); and 'My father was very dismissive. Just said, "There's nothing wrong with him" ' (Mary). Friends' attempts to be supportive were at times seen to perpetuate the stigma felt by carers. For example, Allan described a friend's attempts at encouragement: 'Your son's a genius, there's nothing wrong with him'; as belittling the daily challenges he faced: 'Yes, he is intelligent, but he still has autism'. This attitude of there being nothing wrong led carers to feel isolated in their caring role within the context of their families and friends. Comments describing family and friends' lack of knowledge did not suggest any vindictive motives; 
however, these carers felt stigmatised as many suggested that family and friends should be more willing to learn or attempt to understand. The refusal to accept the challenges associated with HFA from carers' most intimate personal relationships often had major social implications, with just over half of the participants $(n=8)$ reported having very limited contact with their families. The lack of knowledge about HFA was exemplified by several carers who reported that their parents viewed the children with HFA as 'just naughty children' (Tammy), and that they would 'grow out of it' (Kimberly, Carol and Robert). A lack of knowledge was therefore understood as being the root cause of any felt or enacted stigma, and was utilised by carers as a defence mechanism, by apportioning the blame for ignorance on others. Furthermore, the emotional reactions of family members to the child with HFA appeared to resemble reflexive stigma, and even deliberative stigma in relation to how children 'should' behave in socially acceptable ways.

\section{Judgement}

Participants also reflected on experiences where they had personally felt judged by others because of their child, i.e. courtesy stigma. Judgement was an extension of lack of knowledge in the sense that not understanding the nature of HFA meant that others viewed carers and their children through a lens of what they considered 'normal'. Again, there is the appearance here of deliberative stigma responses. Negative judgement was perceived from schools: 'School is judging me, like I am some sort of crackpot . . . I have been through hell at his school with them pointing the finger' (Rachel); and the general public: 'People would say things, "Control your daughter!" . . . [my wife] would end up in tears coming home' (Jack); 'people think. . . just bad parents, bad kids' (Nicole); 'my kids are on view . . . I'm judged because they are a reflection of me . . . constantly judged and misunderstood' (Tammy). Even after disclosing their child's diagnosis to explain their behaviour to others, carers felt judged by those who dismissed this explanation and inferred that the real issue was a lack of discipline: 'that child just needs a good smack on the bum' (Carol); 'they seem to give you dirty looks and comments like "give them a clip around the ears"' (Peter). Comments and reactions from members of the public demonstrate some very obvious examples of enacted stigma. This created a great deal of distress for several carers, often resulting in their withdrawal from the public sphere: 'it's easier to stay home' (Anna). As well as highlighting enacted stigma, the judgement domain clearly demonstrates carers' experiences of felt stigma, reflecting their emotional reactions and frustrations as a result of other people's lack of knowledge.

As with the lack of knowledge, experiences within the judgement domain extended to carers' family and friends. The perception of being judged as a bad parent was described by participants as being particularly painful: 'My family judges me all the time . . . "it's just poor parenting" ' (Anna); 'You should control your child . . . I'd never let my children act like that' (Robert). Carers again experienced stigma when family and friends questioned their parenting abilities. Participants recounted friends and family members making judgemental comments such as: 'Some people shouldn't be parents' (Carol). As upsetting as judgement from wider public sources could be, carers reflected on the enacted stigma demonstrated through judgement from family and friends as even more distressing. These negative interactions within close personal relationships are in direct opposition to the empathy, support and understanding carers had hoped to find. As such, carers were often unsure of how to handle these situations of judgement, which exacerbated their feelings of social isolation and hurt.

\section{Rejection}

As well as feeling judged by others, participants reported a direct sense of rejection. These feelings of rejection were directed at carers and their children alike, but carers expressed a 
sense of personal rejection in either case, i.e. they felt courtesy stigma when their children were rejected. Some believed that schools would prefer their children not to attend, based on the school's interactions both with the children: 'Principals don't want our kids . . . because they are too much hard work' (Allan); and carers: 'The answer is no, even before [the principal] has heard what I have to say. . . He wouldn't dare say that to [a parent] who has got six normal kids' (Tammy). Rejection was also experienced in the broader public sphere, including interactions with other parents: 'His behaviour would just freak them out. [Other parents] just would not talk to me' (Rachel); and prospective employers: 'People won't hire me because of my kids' (Kimberly). Again, this highlights the courtesy stigma carers felt through perceiving a rejection of their child. If their perceptions of others' behaviour were accurate, then it is likely that reflexive and deliberative stigma were both underpinning the responses of teachers and principals to their children's behaviour. That is, their child was seen to enter a school environment that was socially determined in relation to what was 'good' and 'appropriate' behaviour, a behaviour style that their child could not always display.

Nine participants described feeling rejected by their own families. Despite a desire to maintain family connections, these carers did not feel that other family members were willing to accommodate their children. This resulted in family gatherings becoming 'just a horrible experience' (Anna). Consequently, they felt there was no option but to 'withdraw a lot from family gatherings . . . 'cause (a) it's too hard on us and (b) it's too hard on the big guy' (Robert). Similarly, a sense of rejection existed among carers' existing friendship circles: 'We have lost all our friends . . . because of their attitude towards [child]' (Carol). Rejection was the most commonly described domain in relation to carers' friends, with 12 participants expressing sadness and disappointment over the loss of existing friendships and resultant social isolation: 'We lost our old friends. Because they didn't want to be around a screaming child who behaved so poorly' (Betty); 'no friendships, because you have been sitting inside a house for 5 years. Lost all contact with the outside world' (Tammy); 'We lost a lot of friends because no one wants to hang out with people with a baby that's screaming and yelling and bashing against the wall' (Jack). As with judgement, the felt and enacted stigma experienced through rejection from family members and friends were particularly hurtful to carers, most commonly resulting in their social withdrawal. Rejection from wider public sources was often met with a sense of anger, whereas rejection from family and friends was described as having a much more significant and emotionally charged impact, and was more likely to alter carers' behaviour through strategies such as social withdrawal.

\section{Lack of support}

At a more practical level, carers reported a lack of support as characterising their stigmatising experiences. This was a common perception among carers whose children were attending mainstream schools, demonstrated by those who stated: 'They [school] don't want to make anything easier . . . they are just non-cooperative' (Rachel); and 'We gave him all these flash cards . . . they [teachers] just haven't used them . . . it's been very, very annoying' (Robert). Carers felt that schools did not support them in attempting to improve their children's educational experiences. While this domain did not reflect any malicious intent, a lack of support in caring for a child with additional needs was generally understood as felt stigma. Reflective of the judgemental attitudes perceived to be held by the public, participants reported a general lack of support with comparatively few positive experiences. This is best demonstrated by Robert, who described 'a couple of instances where strangers show kindness . . . but equally there have been a lot more people that have sent the sly and stupid comments our way'. Carers appeared to be much more aware of the negative reaction from strangers than they were of kind acts. In this sense, carers described a worldview characterised by felt stigma, which in turn appeared to be generated by reflexive and deliberative stigma. 
Carers also perceived a lack of support from their families and friends, and indicated that this was particularly difficult to deal with - both practically and emotionally: 'My family are not really supportive. . . makes it really hard' (Anna). Lack of support from within these personal circles had particular practical implications for several carers, as suggested by the following statements: 'No one could or would help me with taking him to all these appointments' (Nicole); 'I can't leave him with my mother 'cause she doesn't lock the house up properly and he gets away from her. So I don't have a life' (Kimberly). Unlike the lack of support from schools and the public, within the context of the family, carers experienced personal limitations and inconveniences. Their frustrations at not being able to rely on their own family were particularly apparent. The expectation was that family members should be available for babysitting from time to time, and the lack of such support was particularly disappointing. Participants also felt particularly unsupported by friends under circumstances such as that described by Allan: 'My friend's sons called my son a "freak" . . . Their parents should have acted on them. But they didn't . . . I felt let down'. Instances such as this not only demonstrate a lack of practical support experienced by these carers but also highlight an associated lack of knowledge and judgemental attitudes (as described in previous domains). Lack of support highlights carers' expectations of how others should act. They expected that people close to them would provide both practical and emotional support, and described the disappointment associated with felt stigma when this reality did not eventuate. This domain demonstrates at a practical level how the relationship dynamics play out among friends and family when stigma is perceived.

\section{Resilience and coping}

As interviews focused on carers' experiences of stigma, a great deal of conversation was negatively framed. Despite this, participants also demonstrated their resilience and a capacity to cope with the stigmatising challenges they had faced. Participants were recruited through autism support groups, so it is not surprising that these groups were described as being a positive resource for carers: 'the support groups probably is the one thing that helped me hold together when I was here because I had nowhere else to really meet people with similar things' (Nicole). Additional sources of social support were identified by some carers, e.g. 'The pastor's wife lives just around the corner . . . she gets it' (Rachel); 'The mums from the school have been quite a surprising support network for me' (Anna). Even though carers felt stigma pervading their social worlds, they were also able to identify sources of positive engagement and support.

In facing stigmatising experiences, several participants described how they had attempted to educate others and thus reduce future stigma. This idea of educating others was best described by Anna, who stated, 'I really want to help spread awareness . . . just autism awareness and educating people'. Through raising awareness and educating others, it was believed that stigma as a result of a lack of knowledge would eventually dissipate. Similarly, the notion of advocacy was raised as a means of dealing with stigma, particularly enacted stigma. The tendency to advocate for their children was common among participants: 'you have to fight battles for them . . . mums and parents of kids with disabilities are very proactive' (Nicole). This proactive nature enabled carers to confront stigma and develop a sense of competence, rather than accept oppressive situations.

Alongside these proactive strategies, a number of carers reported avoiding social interaction as a means of avoiding stigma (as outlined in the section on 'Rejection'). Carers perceived social withdrawal as an unfortunate means of dealing with stigma, and was generally a last resort: 'I am trying everything. I don't know, I mean apart from trying to education them to understand, is really to avoid these situations. Which is pretty sad' (Anna). 
Despite the challenges these carers reported, particularly regarding felt stigma, they simultaneously reported overwhelmingly positive experiences in relationship with their children. While acknowledging the ups and downs of caring for a child with HFA, they clearly articulated the joy and love they experienced: 'He makes me laugh. He is a hilarious child' (Nicole); 'Frustrating but also insanely rewarding' (Peter). The love these carers felt towards their children was a major motivation behind other strategies they employed to deal with stigma, as their primary concern was to provide their children with the most stable and supportive environments they could in any given context.

\section{Discussion}

The results of this study revealed four domains that characterised stigmatising experiences for carers of children with HFA: (i) lack of knowledge, (ii) judgement, (iii) rejection and (iv) lack of support. These domains were described in relation to four main contexts within carers' lives: (i) school, (ii) public, (iii) family and (iv) friends. The framework of these domains and contexts provide a detailed account of how and where participants felt stigmatised. Insight into these experiences can inform ways of supporting carers to cope when encountering stigma, and also direct attempts to reduce its occurrence.

The four distinct domains identified in this study did not occur in isolation. Rather, carers generally described stigma as a progression through these four related domains. For example, when carers perceived a lack of knowledge about HFA and its associated challenges (e.g. from friends, family members, teachers or members of the public), they felt as though they were being judged as poor parents. Feeling judged often led carers to feel rejected by others, and consequently not supported. The four domains therefore demonstrate a common stigmatising pathway. Once a carer had experienced this pathway within one context (e.g. family), it appeared more likely that they would perceive similar stigmatising experiences within another context (e.g. school). Several carers in this study viewed stigma as a pervasive feature of their lives, with these perceptions significantly inhibiting their ability and willingness to engage in normal social activities across contexts. In this way, the domains reflect how felt stigma can influence a carer's worldview across multiple contexts.

Importantly, carers were able to identify examples of felt stigma irrespective of the length of time they had been caring for a child with HFA. There were distinct similarities throughout participants' stories whether their child had been diagnosed within the preceding few years or closer to a decade previously. Many reflected on the benefits of support groups and people they could relate to in the early stages after diagnosis, but reactions from external sources remained similar over time. The build-up of rejection and no support over a period of time appeared to contribute to more felt stigma (and personal feelings of distress), but over time, carers also developed greater awareness of support options available to them and were able to instigate their own coping strategies. Regardless of the type of stigma reported by parents whether this be enacted, felt or courtesy; deliberative or reflexive - carers who were negatively affected by stigma appeared to become enmeshed in the stigmatising comments and attitudes of others. On the other hand, carers who had experienced positive responses towards themselves and their children possessed an interpretive foundation that seemed to help them avoid enmeshment in others' stigmatising comments and behaviour. For instance, carers who participated in proactive strategies such as educating others seemed to take a level of control over stigmatising situations. In doing so, they seemed to avoid enmeshment in what was the inability of people to accept their children's behaviour as a normal part of an HFA child's life. Participation in support groups also seemed to have this ameliorating effect.

Throughout interviews, carers recounted feeling personally stigmatised through perceived discrimination against their children. This was particularly the case in actions from school 
teachers and principals, which was seen to be unfair. Although this 'unfair' treatment was directed at their children, many carers took it personally. Coupled with deliberative stigma that was directed at their parenting abilities, this courtesy stigma exacerbated the potentially damaging consequences of the overall experience of felt stigma.

If the concept of becoming enmeshed in another's stigmatising responses is valid, then parents' coping strategies such as secrecy regarding their child's diagnosis of HFA, or social withdrawal by the family unit, would be understandable. These seemed to be coping strategies of escape from otherwise toxic circumstances created by people outside their own lives and the lives of their children. Parents who felt bombarded by the stigma of others suggested that these coping strategies exacerbated negative experiences, by increasing social isolation and/or emotional distress. In another vein, while some carers described using their knowledge and experience in attempting to educate others, with a positive outcome resulting in at least some sectors of influence, the potential also existed for this level of effort to become unnecessarily burdensome.

The concept of enmeshment and control in the face of stigma has the potential to inform structures of support for carers of HFA children. As with any experiences in life where the attitudes and behaviours of other people have deleterious effects, control over these experiences is taken away from the person who is targeted. Generally speaking, no individual can control the thoughts or beliefs of other people, and stigma is a phenomenon that arises primarily from the thinking patterns of people who believe that the world should be seen in a particular way. The reality is that for some people, children with HFA will not 'fit' into their manageable view of the world, and so will be criticised at best and excluded at worst. As suggested by previous literature, and supported by this study, parents of these children often take stigmatising responses of this type into their lives as if they were valid.

Attempts to empower carers in the face of stigmatisation are likely to benefit from considering each of the domains identified in this study and the pathway that connects them. Supporting carers in responding to perceived judgement from others is likely to be most effective when related experiences across the other domains are similarly addressed. Similarly, providing carers with the support they lack from other sources, while beneficial, is unlikely to completely negate experiences of stigma in terms of judgement and rejection in other contexts. However, it may serve to alter how carers perceive and respond to any such judgement or rejection.

It is therefore important that carers are provided with necessary support, and that an awareness of the unique nature of HFA is promoted throughout communities and across different social contexts. The importance of ongoing support and understanding of the nature of HFA and its impacts on family units is also emphasised through this study. As demonstrated by the suggestion of a stigmatising pathway, the negative psychosocial impacts of perceiving stigma can be exacerbated over time and recurring experiences, particularly when these occur throughout multiple social contexts. While contexts such as the family may be clearly differentiated from the child's school, the similarities of carers' perceptions of stigma across these contexts highlight the importance of supporting and advocating for these children, their carers and their families in all social arenas.

These carers place the needs of their children on high priority. Acceptance of others' ignorance through stigma scaffolds this commitment and protects it from becoming eroded by this ignorance, as if what others believe and say is valid. Where carers are helped to exercise acceptance of and commitment to their children in the face of negative reaction by others, then the likely outcome is that they will in turn strengthen this commitment towards their children as well as their commitment to themselves as 'good and caring' parents. The 
alternative is to take stigmatising, negative responses on board as true, and consequently diminish their efforts and love on behalf of their children, and worse, see themselves as inept.

A caveat exists when considering support programmes with parents that are based on the notion of acceptance and commitment. Murrell and Scherbarth (2011), in their literature review of interventions founded on Acceptance and Commitment Therapy, highlight the potential barrier of felt parental incompetence. In relation to HFA, carers who feel overwhelmed by the stigmatising responses of others, and who consequently diminish their caring competency, are at risk of avoiding supportive groups and programmes as these might serve to highlight this felt incompetence.

The existence of carers' coping strategies is again worth highlighting. Whether the ensuing outcomes improved situations (e.g. finding alternative supports or changing other people's perceptions) or further exacerbated problems (e.g. social withdrawal), carers in this study demonstrated varying degrees of resilience. It is important to note the emergence of these themes of strength and resilience in a project that primarily focused on negative experiences. Regardless of the challenges faced by stigmatising experiences, these carers indicated that not all was 'doom and gloom', but rather, there was always a positive aspect to their caring experience.

The present study was limited in terms of the representativeness of the sample, with participants located only in Sydney and the South Coast regions of New South Wales, and the socio-demographic characteristics of the families being somewhat similar. Caution should therefore be exercised before generalising the present findings to broader HFA carer populations. Further research involving carers from wider geographical and sociodemographic backgrounds may well suggest the existence of additional domains of stigma beyond those identified in this study. Furthermore, the nuances of how carers understand these various domains may differ across broader populations. Nevertheless, their reports of stigmatising experiences reflect those reported in a great deal of previous literature regarding carers of children with autism. This suggests that the pathway of stigmatisation may well be generalisable to broader populations of carers of children with HFA.

Ultimately, this study contributes to broader understandings of social experiences among this particular population of carers. In particular, experiences that are interpreted as stigmatising can be seen to exist along a pathway. Through identifying this pathway, services and/or individuals who aim to provide support to carers of children with HFA can be acutely aware of how carers' thought processes are liable to progress when they experience and perceive stigma, and thus provide appropriate intervention for the relevant stage of this pathway.

\section{References}

Bertaux D. (1981) From the life-history approach to the transformation of sociological practice. In: D. Bertaux (Ed.) Biography and Society: The Life History Approach in the Social Sciences, pp. 29-45. Sage, London.

Blum L.M. (2007) Mother-blame in the Prozac Nation: raising kids with invisible disabilities. Gender \& Society 21, 202-226.

Broady T. (2013) Resilience across the continuum of care. M/C Journal 16, http://journal.media-culture.org.au/index.php/mcjournal/article/viewArticle/698.

Carers NSW (2014) Carers NSW 2014 Carer Survey: Main Report. Carers NSW, Sydney. 
Estes A., Munson J., Dawson G., Koehler E., Zhou X.-H. \& Abbott R. (2009) Parenting stress and psychological functioning among mothers of preschool children with autism and developmental delay. Autism 13, 375-387.

Farrugia D. (2009) Exploring stigma: medical knowledge and the stigmatisation of parents of children diagnosed with autism spectrum disorder. Sociology of Health \& Illness 31, 10111027.

Fletcher P.C., Markoulakis R. \& Bryden P.J. (2012) The costs of caring for a child with an autism spectrum disorder. Issues in Comprehensive Pediatric Nursing 35, 45-69.

Gill J. \& Liamputtong P. (2013) Walk a mile in my shoes: life as a mother of a child with Asperger's syndrome. Qualitative Social Work 12, 41-56.

Goffman E. (1963) Stigma: Notes on the Management of Spoiled Identity. Prentice Hall, Englewood Cliffs, NJ.

Gray D.E. (1993) Perceptions of stigma: the parents of autistic children. Sociology of Health \& Illness 15, 102-120.

Gray D.E. (2002) 'Everybody just freezes. Everybody is just embarrassed': felt and enacted stigma among parents of children with high functioning autism. Sociology of Health \& Illness 24, 734-749.

Gray D.E. (2003) Gender and coping: the parents of children with high functioning autism. Social Science \& Medicine 56, 631-642.

Gray D.E. (2006) Coping over time: the parents of children with autism. Journal of Intellectual Disability Research 50, 970-976.

Green S.E. (2001) 'Oh, those therapists will become your best friends': maternal satisfaction with clinics providing physical, occupational and speech therapy services to children with disabilities. Sociology of Health \& Illness 23, 798-828.

Green S.E. (2003) "What do you mean 'what's wrong with her?'”: stigma and the lives of families of children with disabilities. Social Science \& Medicine 57, 1361-1374.

Griffith G.M., Totsika V., Nash S., Jones R.S.P. \& Hastings R.P. (2012) "We are all there silently coping". The hidden experiences of parents of adults with Asperger syndrome. Journal of Intellectual and Developmental Disability 37, 237-247.

Jacoby A. (1994) Felt versus enacted stigma: a concept revisited: evidence from a study of people with epilepsy in remission. Social Science \& Medicine 38, 269-274.

Landsman G.H. (1998) Reconstructing motherhood in the age of "perfect" babies: mothers of infants and toddlers with disabilities. Signs 24, 69-99.

Lee G.K. (2009) Parents of children with high functioning autism: how well do they cope and adjust? Journal of Developmental and Physical Disabilities 21, 93-114.

Lilley R. (2013) It's an absolute nightmare: maternal experiences of enrolling children diagnosed with autism in primary school in Sydney, Australia. Disability \& Society 28, 514526.

Ludlow A., Skelly C. \& Rohleder P. (2012) Challenges faced by parents of children diagnosed with autism spectrum disorder. Journal of Health Psychology 17, 702-711.

Lutz H.R., Patterson B.J. \& Klein J. (2012) Coping with autism: a journey toward adaptation. Journal of Pediatric Nursing 27, 206-213. 
McKeever P. \& Miller K.-L. (2004) Mothering children who have disabilities: a Bourdieusian interpretation of maternal practices. Social Science and Medicine 59, 11771191.

Murrell A.R. \& Scherbarth A.J. (2011) State of the research \& literature address: ACT with children, adolescents and parents. International Journal of Behavioral Consultation and Therapy 7, 15-22.

Olsson M.B. \& Hwang C.P. (2001) Depression in mothers and fathers of children with intellectual disability. Journal of Intellectual Disability Research 45, 535-543.

Pryor J.B., Reeder G.D., Yeadon C. \& Hesson-McInnis M. (2004) A dual-process model of reactions to perceived stigma. Journal of Personality and Social Psychology 87, 436-452.

Pryor J.B., Reeder G.D. \& Monroe A.E. (2012) The infection of bad company: stigma by association. Journal of Personality and Social Psychology 102, 224-241.

Rocque B. (2010) Mediating self-hood: exploring the construction and maintenance of identity by mothers of children labeled with autism spectrum disorder. Disability \& Society 25, 485-497.

Ryan S. (2005) 'People don't do odd, do they?' Mothers making sense of the reactions of others towards their learning disabled children in public places. Children's Geographies 3, 291-305.

Ryan S. (2010) 'Meltdowns', surveillance and managing emotions; going out with children with autism. Health \& Place 16, 868-875.

Ryan S. \& Runswick-Cole K. (2008) Repositioning mothers: mothers, disabled children and disability studies. Disability \& Society 23, 199-210.

Scambler G. (2004) Re-framing stigma: felt and enacted stigma and challenges to the sociology of chronic and disabling conditions. Social Theory \& Health 2, 29-46.

Scambler G. \& Hopkins A. (1986) Being epileptic: coming to terms with stigma. Sociology of Health \& Illness 8, 26-43.

Werner S. \& Shulman C. (2013) Subjective well-being among family caregivers of individuals with developmental disabilities: the role of affiliate stigma and psychosocial moderating variables. Research in Developmental Disabilities 34, 4103-4114.

Werner S. \& Shulman C. (2015) Does type of disability make a difference in affiliate stigma among family caregivers of individuals with autism, intellectual disability or physical disability? Journal of Intellectual Disability Research 59, 272-283.

Woodgate R.L., Ateah C. \& Secco L. (2008) Living in a world of our own: the experience of parents who have a child with autism. Qualitative Health Research 18, 1075-1083. 